Formulasi Tablet Hisap Ekstrak Kulit Buah....., Ria, Mufrod, Lutfi

\title{
FORMULASI TABLET HISAP EKSTRAK KULIT BUAH MANGGIS (Garcinia mangostana L.) SEBAGAI ANTIOKSIDAN DENGAN VARIASI KONSENTRASI GELATIN SEBAGAI BAHAN PENGIKAT
}

\author{
Ria Cahya Andriana, Mufrod, Lutfi Chabib \\ Program Studi Farmasi Fakultas Ilmu Pengetahuan dan Alam \\ Universitas Islam Indonesia \\ e-mail : ria.cahyaandriana@gmail.com
}

\begin{abstract}
Peel of mangosteen (Garcinia mangostana L.) contains xanthones especially a-mangostin which have antioxidant activity. The aim on this study was to determine the physical of lozenges extract from mangosteen peel with variation concentration of gelatin $2 \%, 4 \%, 6 \%, 8 \%$ and $10 \%$, also to determine the effect formulations of powder into lozenges made with wet granulation method to the percentage reduction of the free radical. The ability of neutralizing free radicals were tested by treating the extract in DPPH with ratio of 3:1. Results showed the tablet hardness were $10.75 \mathrm{~kg}, 11.13 \mathrm{~kg}, 11.94 \mathrm{~kg}, 12.14 \mathrm{~kg}$ and 12.35 $\mathrm{kg}$. The friability were $0.84 \%, 0.73 \%, 0.71 \%, 0.60 \%$ and $0.50 \%$. Time soluble of the tablet were 7.05 minutes, 9.44 minutes, 9.57 minutes, 11.51 minutes and 13.62 minutes, respectively. Data was analyzed by oneway ANOVA with $95 \%$ confidence level. The results showed that all formulas gave better physical properties on granules and tablets produced. Higher concentration of gelatin decreased friability, increased hardness and time-soluble of lozenges. Formula 5 showed the best physical tablet. Percentage reduction of free radicals of extract with DPPH decreased $70.72 \%$ after formulated into lozenges.
\end{abstract}

Keywords: Mangosteen peel (Garcinia mangostana L.), Lozenges, Gelatin, DPPH (2,2-Diphenyl-1-picrylhidrazyl)

PENDAHULUAN

Buah manggis

(Garcinia mangostana L.) adalah buah asli negara Indonesia, dijuluki sebagai queen of tropical fruits (ratunya buah tropis) yang menyimpan berbagai manfaat bagi kesehatan. Kulit buah manggis mengandung senyawa xanthones terutama a-mangostin yang memiliki aktivitas sebagai antioksidan $^{(1)}$. Aktivitas antioksidan dilaporkan dalam bentuk nilai $\mathrm{IC}_{50}$, didapatkan nilai $\mathrm{IC}_{50}$ sebesar $5,94 \mu \mathrm{g} /$ $\mathrm{ml}$ yang tidak jauh berbeda dengan 
nilai $\mathrm{IC}_{50}$ asam askorbat yakni sebesar $4,30 \mu \mathrm{g} / \mathrm{ml}^{(2)}$. Dilakukan pemanfaatan kulit buah manggis yang diformulasi dalam bentuk tablet hisap sebagai antioksidan.

Tablet hisap adalah sediaan padat yang dapat melepaskan bahan obat dengan lambat serta melarut perlahan kurang dari 30 menit di dalam mulut ${ }^{(3,4)}$. Pembuatan tablet dari ekstrak dengan metode kempa pada saat proses pentabletan akan menghasilkan sifat alir yang kurang baik. Senyawa antioksidan yang terkandung dalam kulit buah manggis stabil pada suhu $65^{\circ} \mathrm{C}^{(5)}$. Oleh karenanya tablet dibuat dengan metode granulasi basah, pengeringan dengan oven pada suhu $45^{\circ} \mathrm{C}$.

Penggunaan gelatin pada konsentrasi 2-7 \% dapat memperbaiki kekompakan, meningkatkankekerasan dan kecepatan disolusi tablet hisap secara oral ${ }^{(6)}$.

Aktivitas peredaman radikal bebas ekstrak kulit buah manggis diuji dengan metode DPPH $(2,2$ Diphenyl-1-picrylhidrazyl) yang dibandingkan dengan tablet hisap serta vitamin E. Hasilnya dibaca dengan spektrofotometri $\lambda 516 \mathrm{~nm}$. Nilai absorbansi untuk menghitung persentase peredaman dan hasilnya dilaporkan sebagai $I C_{50}$, yakni konsentrasi antioksidan untuk menetralkan radikal bebas sebesar 50 \%. Semakin kecil nilai $\mathrm{IC}_{50}$ maka semakin baik kemampuan antioksidannya $^{(7,8)}$.

\section{METODE PENELITIAN}

\section{Bahan :}

Ekstrak kering kulit buah manggis (Garcinia mangostana L.). yang diperoleh dariPT. Jamu BOROBUDUR, DPPH (2,2-diphenyl-1-picrylhydrazyl), vitamin $\mathrm{E}(D$ - $\alpha$-tokoferol), etanol p.a, gelatin, manitol, laktosa, asesulfam $\mathrm{K}$, magnesium stearat, plat silika $\mathrm{GF}_{254}$, fase gerak $n$-heksan dan etil asetat dengan perbandingan $(9: 1)$

\section{Alat :}

Oven, timbangan analitik (Mettler Toledo), bejana kromatografi, pipa kapiler, chamber, lampu UV 254 nm, UV $365 \mathrm{~nm}$, mortir stamper, stopwatch, alat uji sudut diam, alat uji waktu alir, hardness tester (Erweka TBH 125), friabilaty tester (TA-100/TA-200), dan mesin cetak tablet single punch (Delta VFD007S21A), spektrofotometer UV (Spektrofotometer Htachi 2810).

\section{Uji aktivitas antioksidan dengan metode KLT}

Ekstrak kering kulit buah manggis dilarutkan dengan etanol $90 \%$. Dielusi dengan fase gerak $\mathrm{n}$ heksan : etil asetat $(9: 1)$. Plat KLT dikeringkan lalu disemprot dengan larutan DPPH 0,1 $\mathrm{mm}$. Komponen ekstrak yang bersifat antiradikal bebas akan menghasilkan bercak kuning pucat dengan latar belakang ungu setelah 30 menit $^{(9,10)}$.

\section{Perhitungan dosis}

Mengacu pada suplemen yang mengandung Tokoferol 250 IU dalam 1 kapsul yang di konsumsi 1 kali perhari 
Formulasi Tablet Hisap Ekstrak Kulit Buah....., Ria, Mufrod, Lutfi

dengan indikasi sebagai antioksidan. 1 IU secara biologis setara dengan $0,667 \mathrm{mg}$. Maka $250 \mathrm{IU}=166,75 \mathrm{mg}$. Dari hasil uji dengan metode DPPH didapatkan nilai $I C_{50}$ Tokoferol sebesar $1,29 \mathrm{mg}$. Maka dosis obat $\mathrm{X}=129,26$ kali dari nilai $I_{50}$. Dari perhitungan didapatkan nilai $I C_{50}$ ekstrak kulit buah manggis adalah 7,584 mg. Maka :1,29 $: 7,584=5,88$

Dapat disimpulkan bahwa, kemampuanekstrakkulitbuah manggis dibandingkan dengan tokoferol dalam meredam radikal bebas adalah 1 : 5,88 . Maka dosis ekstrak kulit buah manggis dalam sehari adalah sebagai berikut:

$$
\begin{aligned}
129,26 \times 5,88 & =760,0488 \mathrm{mg} \\
& =760 \mathrm{mg} \text { (dibulatkan) }
\end{aligned}
$$

Karena rasa ekstrak kulit buah manggis yang terlampau pahit oleh karenanya dosis dibagi ke dalam 2 tablet. Sehingga tiap tablet mengandung $380 \mathrm{mg}$ ekstrak kulit buah manggis.

\section{Desain formula}

\begin{tabular}{|c|c|c|c|c|c|}
\hline \multirow{2}{*}{ Bahan untuk tiap tablet } & \multicolumn{5}{|c|}{ Komposisi (mg) } \\
\cline { 2 - 7 } & F 1 & F 2 & F 3 & F 4 & F5 \\
\hline \multirow{2}{*}{ Fase dalam } & 380 & 380 & 380 & 380 & 380 \\
\hline Serbuk ekstrak & 952,8 & 952,8 & 952,8 & 952,8 & 952,8 \\
\hline Manitol & 635,2 & 635,2 & 635,2 & 635,2 & 6,352 \\
\hline Laktosa & 32 & 32 & 32 & 32 & 32 \\
\hline Asesulfam K & 2 & 4 & 6 & 8 & 10 \\
\hline Gelatin (\%) & Fase luar (2\% dari berat granul setelah dioven) & & & 7,814 \\
\hline
\end{tabular}

\section{Uji evaluasi sifat granul}

\section{a. Uji kadar air granul}

Granul sebanyak \pm 500 mg dimasukkan pada alat Moisture balance. Kadar air granul dihitung dengan cara menghitung bobot mula-mula granul dikurangi dengan bobot konstan dibagi bobot mulamula dikali $100 \%$

b. Uji waktu alir granul

Sebanyak $100 \mathrm{~g}$ granul dimasukkan dalam corong yang sebelumnya disumbat bagian bawahnya. Setelah itu sumbatan dibuka dan dicatat waktu yang diperlukan untuk semua granul melewati corong.

c. Uji sudut diam granul

Seratus gram granul dimasukkan dalam corong yang sebelumnya bagian bawah corong sudah disumbat. Setelah itu sumbatan dibuka, sehingga terbentuk tumpukan 
granul yang berbentuk kerucut. Tinggi dan diameter granul diukur untuk mengetahui sudut diam granul.

d. Uji pengetapan granul

Gelas ukur $100 \mathrm{ml}$ diisi dengan sejumlah granul, volume dicatat sebagai volume awal. Gelas ukur dipasang pada volumenometer dan dihentakkanhinggavolumekonstan. Pesentase tapping dihitung dengan volume awal dikurangi dengan volume konstan dibagi dengan volume awal dan dikalikan $100 \%$.

\section{Uji sifat fisik tablet hisap}

a. Uji keseragaman bobot

Ditimbang 20 tablet secara acak. Kemudian dihitung bobot rataratanya dan penyimpangan tablet terhadap bobot rata-rata yang

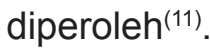

\section{b. Uji keseragaman ukuran}

Diukur diameter dan ketebalan 20 tablet secara acak dengan alat mikrometer. Tablet yang baik memiliki diameter yang tidak lebih dari 3 kali dan tidak kurang dari 1 1/3 tebal tablet. Dari hasil pengukuran dihitung nilai koefisien variasinya untuk mengetahui keseragaman ukuran tablet.

\section{c. Uji kerapuhan}

Sebanyak 20 tablet ditimbang dan dicatat bobotnya. Kemudian tablet dimasukkan ke dalam alat friabilator selama 4 menit dengan kecepatan putaran sebanyak 25 putaran per menitnya. Tablet dibersihkan dari serpihan yang terbentuk, lalu ditimbang kembali dan dihitung bobotnya.

\section{d. Uji kekerasan}

Diambil sebanyak 20 tablet secara acak. Tablet diletakkan pada alat hardness tester dengan posisi horizontal ditunggu hingga tablet pecah atau retak. Dibaca nilai yang tertera pada monitor alat.

\section{PembuatanlarutanstandarDPPH} (2,2-diphenyl-1-picrylhydrazyl)

Sebanyak $6 \mathrm{mg}$ DPPH dilarutkan dengan etanol $90 \%$ hingga batas 100 $\mathrm{ml}$. Lalu diuji dengan spektrofotometer untuk menentukan $\lambda$ maksimum yang diamati pada $\lambda$ 400-600 nm. Setelah itu nilai absorbansinya dibaca dan hasilnya dijadikan sebagai absorbansi kontrol untuk menghitung persentase peredaman.

\section{Pembuatan larutan uji}

Larutan uji yang dibuat terdiri dari larutan vitamin E (D- $\alpha$-tokoferol), ekstrak kering kulit buah manggis yang dilarutkan, dan larutan tablet (formula terbaik) dengan seri konsentrasi bervariasi dengan pelarut etanol $90 \%$.

Penentuan kemampuan menetralkan radikal bebas DPPH dari larutan uji

Masing-masing sebanyak $1 \mathrm{ml}$ larutan uji dengan berbagai variasi konsentrasi ditambahkan pada $3 \mathrm{ml}$ larutan $\mathrm{DPPH}$, divortex selama 1 menit, didiamkan selama 30 menit 
Formulasi Tablet Hisap Ekstrak Kulit Buah....., Ria, Mufrod, Lutfi

lalu dibaca absorbansinya pada $\lambda$ didapat dari PT. Industri Jamu maksimum.

\section{HASIL DAN PEMBAHASAN}

Ekstrak kering kulit buah manggis

Borobudur. Proses ekstraksi dilakukan menggunakan ethanol $70 \%$. Proses penyerbukan dari bentuk ekstrak dilakukan dengan vacum belt dryer.

\begin{tabular}{|c|c|}
\hline $\begin{array}{c}\text { Jenis } \\
\text { identifikasi }\end{array}$ & Hasil \\
\hline Bentuk & Serbuk (powder) \\
\hline Ukuran partikel & 25 mesh \\
\hline Wama & Coklat cerah (light brown) \\
\hline Aroma & Khas (aromatic) \\
\hline Rasa & Pahit (bitter) \\
\hline Kadar air & $5 \%$ \\
\hline Eksipien & Maltodektrin $15 \%$ \\
\hline $\begin{array}{c}\text { Cara } \\
\text { penyimpanan }\end{array}$ & $\begin{array}{c}\text { Tempat sejuk \& kering, } \\
\text { terhindar dari cahaya \& panas }\end{array}$ \\
\hline
\end{tabular}

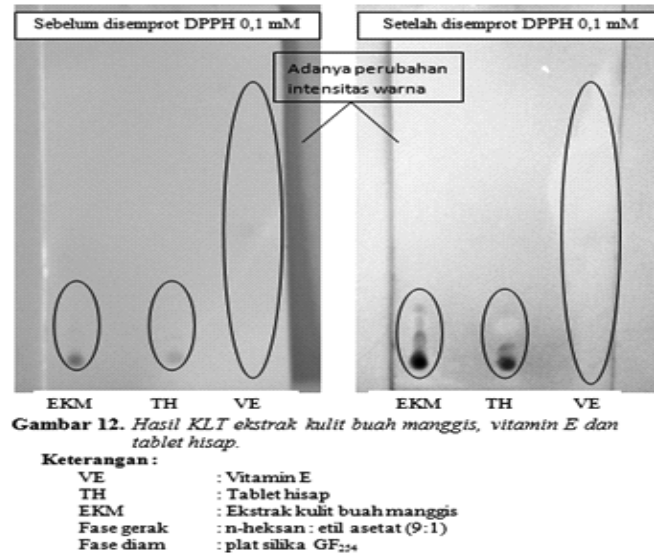

Bercak berwarna kuning ini merupakan bentuk adanya reaksi antara senyawa yang bersifat antioksidan dengan $\mathrm{DPPH}^{(7)}$.

\begin{tabular}{|c|c|c|c|c|c|c|}
\hline \multirow{2}{*}{$\begin{array}{l}\text { Uji sifat fisik } \\
\text { granul }\end{array}$} & \multicolumn{5}{|c|}{ Formula } & \multirow[b]{2}{*}{$\mathrm{FI}=$ Formula 1} \\
\hline & I & II & III & IV & V & \\
\hline Kadar air (\%) & $3,31 \pm 0,20$ & $3,27 \pm 0,29$ & $3,12 \pm 0,14$ & $3,06 \pm 0,22$ & $2,02 \pm 0,12$ & FII $=$ Formula 2 \\
\hline Waktu alir (s) & $7,19 \pm 0,34$ & $6,35 \pm 0,20$ & $6,23 \pm 0,10$ & $5,98 \pm 0,13$ & $5,82 \pm 0,15$ & $\begin{array}{c}\text { FIII }=\text { Formula } \\
3\end{array}$ \\
\hline Sudut diam $\left(^{\circ}\right)$ & $30,22 \pm 0,26$ & $29,12 \pm 0,62$ & $29,06 \pm 1,31$ & $28,26 \pm 1,21$ & $27,80 \pm 1,21$ & $\begin{array}{c}\mathrm{FIV}=\text { Formula } \\
4\end{array}$ \\
\hline $\begin{array}{c}\text { Pengetapan } \\
(\%)\end{array}$ & $19,8 \pm 1,10$ & $19,6 \pm 1,14$ & $18,2 \pm 0,84$ & $14,6 \pm 2,30$ & $13,4 \pm 2,51$ & $\mathrm{FV}=$ Formula 5 \\
\hline
\end{tabular}

Peningkatan konsentrasi gelatin dapat menurunkan kadar air, waktu alir sdut diam serta persentase pengetapan. Hal ini karena, semakin tinggi konsentrasi bahan pengikat berarti bahwa konsentrasi air lebih sedikit jika dibandingkan dengan formula dengan konsentrasi gelatin yang rendah. Kadar air granul yang baik 2-3\%.

Peningkatan konsentrasi gelatin dapat menyebabkan terbentuknya daya ikat antargranul yang semakin kuat sehingga gaya kohesinya meningkat dan gaya adhesinya semakin kecil maka mobilitas granul 
semakin cepat, gaya gesek antar granul rendah sehingga menghasilkan waktu alir granul yang semakin cepat serta granul mengalir dengan baik dan bebas (freeflowing) maka terbentuknya sudut diam yang semakin kecil.

Selain itu juga terbentuknya fines sedikit maka ketika adanya penge- tapan, tidak adanya pengisian ruang antargranul oleh fines sehingga dihasilkannya persentase pengetapan yang rendah. Waktu alir yang baik adalah kurang dari 10 detik. Sudut diam yang baik adalah $30^{\circ}$ dan persentase pengetapan yang baik $<25 \%$.

\begin{tabular}{|c|c|c|c|c|c|}
\hline \multirow{2}{*}{ Sifat fisik tablet } & \multicolumn{5}{|c|}{ Formula } \\
\cline { 2 - 6 } & I & II & III & IV & V \\
\hline Bobot Tablet (g) & $2,02 \pm 0,02$ & $2,02 \pm 0,01$ & $2,05 \pm 0,01$ & $2,06 \pm 0,01$ & $2,05 \pm 0,01$ \\
\hline Ketebalan (mm) & $6,31 \pm 0,02$ & $6,37 \pm 0,02$ & $6,45 \pm 0,03$ & $6,46 \pm 0,02$ & $6,04 \pm 0,01$ \\
\hline Diameter (mm) & $20,14 \pm 0,01$ & $20,13 \pm 0,02$ & $20,09 \pm 0,00$ & $20,08 \pm 0,01$ & $20,10 \pm 0,05$ \\
\hline Kerapuhan (\%) & $0,84 \pm 0,06$ & $0,73 \pm 0,10$ & $0,71 \pm 0,08$ & $0,60 \pm 0,05$ & $0,50 \pm 0,06$ \\
\hline Kekerasan $(\mathrm{kg})$ & $10,75 \pm 0,64$ & $11,13 \pm 0,62$ & $11,94 \pm 0,62$ & $12,14 \pm 0,72$ & $12,35 \pm 0,5$ \\
\hline
\end{tabular}

Peningkatan konsentrasi gelatin menghasilkan granul dengan ikatan antarpartikel yang kuat sehinggagranul dapat dengan mudah mengisi ruang cetak mesin tablet (punch). Sehingga variasi keseragaman bobot menjadi kecil. Adanya variasi konsentrasi gelatin tidak mempegaruhi parameter ketebalan dan diameter tablet karena hal tersebut dipengaruhi oleh ukuran cetakan (punch).

Semakintinggikonsentrasipengikat gelatin mengakibatkan terbentuknya ikatan antarpartikel yang semakin kuat sehingga ketika granul dikompresi menjadi bentuk tablet menghasilkan tablet dengan kekerasan yang tinggi dan tidak mudah rapuh (\% kerapuhan rendah) ketika mengalami goncangan. Tablet hisap yang baik memiliki kekerasan antara 7-15 kg serta \% kerapuhan tidak lebih dari $1 \%$

Berdasarkan keseluruhan hasil uji sifat fisik, dari kelima formula didapatkan formula terbaik yakni formula 5 . Selanjutnya dilakukan uji evaluasi untuk melihat pengaruh formulasi terhadap kemampuan menangkal radikal bebas dari ekstrak kering kulit buah manggis. pada konsentrasi larutan $10 \mathrm{ppm}$, hanya terbaca sebesar 2,928 ppm. Maka terjadi penurunan kemampuan penetralan radikal bebas sebesar 70,72 \%. Dapat disimpulkan bahwa proses formulasi esktrak kulit buah manggis menjadi bentuk sediaan tablet hisap sangat berpengaruh terhadap aktivitas penetralan radikal bebas. Sebagian senyawa antioksidan mengalami oksidasi selama proses formulasi menjadi bentuk sediaan tablet hisap. 
Formulasi Tablet Hisap Ekstrak Kulit Buah....., Ria, Mufrod, Lutfi

\begin{tabular}{|c|c|c|c|c|c|c|c|c|c|c|}
\hline \multirow{2}{*}{ Uji hedonik } & \multicolumn{2}{|c|}{ F I } & \multicolumn{2}{|c|}{ FII } & \multicolumn{2}{|c|}{ F III } & \multicolumn{2}{|c|}{ F IV } & \multicolumn{2}{|c|}{ F V } \\
\hline & S & TS & S & TS & $\mathrm{S}$ & TS & $\mathrm{S}$ & TS & $\mathrm{S}$ & TS \\
\hline Warna & 18 & 2 & 18 & 2 & 16 & 4 & 17 & 3 & 16 & 4 \\
\hline Aroma / bau & 12 & 8 & 11 & 9 & 11 & 9 & 11 & 9 & 10 & 10 \\
\hline Rasa & 15 & 5 & 9 & 11 & 7 & 13 & 6 & 14 & 5 & 15 \\
\hline Waktu larut & \multicolumn{2}{|c|}{7,05} & \multicolumn{2}{|c|}{9,44} & \multicolumn{2}{|c|}{9,57} & \multicolumn{2}{|c|}{11,51} & \multicolumn{2}{|c|}{13,62} \\
\hline Formula disukai & \multicolumn{2}{|c|}{20 orang } & \multicolumn{2}{|c|}{ - } & \multicolumn{2}{|c|}{ - } & \multicolumn{2}{|c|}{ - } & \multicolumn{2}{|c|}{ - } \\
\hline
\end{tabular}

Keterangan:

Formula I = konsentrasi pengikat gelatin $2 \%$

Formula II = konsentrasi pengikat gelatin $4 \%$

Formula III = konsentrasi pengikat gelatin $6 \%$

Formula IV = konsentrasi pengikat gelatin $8 \%$

Formula $\mathrm{V}=$ konsentrasi pengikat gelatin $10 \%$

$\mathrm{S}=$ Suka (orang)

TS = Tidak suka (orang)

Variasi konsentrasi gelatin tidak pengikat yang sama. Dari kelima berpengaruh terhadap warna, aroma formula didapatkan hasil waktu larut serta rasa tablet. Namun didapat- yang sesuai, waktu larut tablet hisap kan hasil uji yang bervariasi karena yang diperbolehkan adalah kurang subyektifitas dari responden. Semakin tinggi konsentrasi pengikat gelatin dihasilkan tablet hisap dengan kekerasan yang semakin tinggi pula. Oleh karenanya waktu melarut tablet hisap menjadi semakin lama. Waktu larut suatu tablet hisap tidak hanya tergantung pada konsentrasi bahan pengikatnya tetapi juga tergantung dari kadar saliva dari seseorang. Orang yang memiliki kadar saliva yang lebih tinggi, tablet dapat lebih cepat terlarut

di dalam mulut. Sedangkan responden dengan kadar saliva rendah, tablet lebih lama terlarut di dalam mulut meskipun tablet yang dihisap adalah tablet dengan konsentrasi bahan dari 30 menit.

\section{KESIMPULAN}

Variasi pengikat gelatin dapat mempengaruhi sifat fisik tablet hisap ekstrak kulit buah manggis. Semakin tinggi konsentrasi gelatin akan meningkatkan kekerasan tablet sebesar $1,6 \mathrm{~kg}$, memperlama waktu larut 6,57 menit, serta menurunkan kerapuhan tablet sebesar $0,34 \%$. Persentase peredaman radikal bebas ekstrak kulit buah manggis terhadap DPPH mengalami penurunan sebesar $70,72 \%$ setelah diformulasi menjadi bentuk sediaan tablet hisap. 


\section{SARAN}

Perlu dilakukan penelitian lebih lanjut untuk memperbaiki rasa, waktu larut serta aroma dan warna agar didapatkan tablet hisap yang lebih menarik dan dapat diterima. Perlu dilakukan kajian lebih lanjut dalam pemanfaatan pohon buah manggis khususnya kulit manggis dalam bentuk sediaan lain agar selama proses formulasinya tidak merusak aktivitas dari kandungan senyawa antioksidan.

\section{DAFTAR PUSTAKA}

Pothitirat, W., and Gritsanapan, W., 2009, HPLC Quantitative Analysis Method for the Determination of a-Mangostin in Mangosteen Fruit Rind Extract, Journal of Agricultural Science, 42 (1) :7-12. Palakawong, C., Sophanodora, P., Pisuchpen, S. and Phongpaichit, S., 2010, Antioxidant and antimicrobial activities of crude extracts from mangosteen (Garcinia mangostana L.) parts and some essential oils, International Food Research Journal, 17: 583-589.

Mendes R. W., and Bhargava, H., 2007,

Lozenges in Swarbrick, James, Encyclopedia Of Pharmaceutical Technology 6 Vols 3rd ed, USA, 2231-2235.

Anonim., 1995, Farmakope Indonesia,

Edisi IV, Departemen Kesehatan Republik Indonesia, Jakarta.

Satong, W., Assawarachan, R., and Noomhorm, A., 2011, The Influence of Drying Temperature and Extraction Methods on a-Mangostin in Mangosteen Pericarp, Journal of Science and Engineering 1 : 85-92. Podczeck, F., 2009, Gelatin, In Rowe, Raymond C, heskey, Paul J., and Quinn, Marian E., (Eds.), Handbook of Pharmaceutical Excipients, Sixth Edition, Pharmaceutical Press and American Pharmacists Association, London, 278-281. Joon, K. W., 2009, Antioxidant Assays for Plant and Food Components, J.Agric. Food Chem, 57: 6655-6166. Prior, R. R., Wu, X., and Schaich, K., 2005, Standarized Methods for The Determination Of Antioxidant Capacity and Phenolics in Foods and Dietary Suplements, J. Agric. Food Chem, 53 (6):1849.

Demirezer, L. O., Kruuzum, U. A., Bergere, I., Schiewe, H. J., and Zeeck, A., 2001, The structures of antioxidant and cytotoxic agents from natural source: antraquinones and tannin from roots of Rumex patientia. Phytochemistry, 58:1213-1217.

Cavin, A., Hostetman, K., Dyatmiko, W., and Potterat, O., 1998, Antioksidant and Lipophilic Constituents of Tinospora Crispa. Planta Medica 64 : 393-396.

Dinas kesehatan., 1979, Simplisia, Farmakope Indonesia, Edisi III, Departemen Kesehatan Republik Indonesia, Jakarta, 28-29. 